\title{
Severe acute postoperative airway compromise secondary to submandibular sialadenitis
}

\author{
Brittney M. Clark, MD • Matthew L. Carlson, MD • Jamie J. Van Gompel, MD • \\ Matthew A. Warner, MD
}

Received: 27 April 2018/Revised: 22 May 2018/Accepted: 22 May 2018/Published online: 5 June 2018

(C) Canadian Anesthesiologists' Society 2018

A 68-yr-old woman developed left-sided submandibular swelling following right retrosigmoid craniotomy for excision of a vestibular schwannoma. The procedure was performed with the patient supine and her head rotated to the left and flexed while fixed with Mayfield pins. Two hours after extubation, she developed firm left-sided submandibular swelling that progressed markedly over the next $12 \mathrm{hr}$, with extension from the tragus to the sternal notch. Computed tomography (Figure, panel $A$ ) revealed acalculous submandibular sialoadenitis (white arrow) with

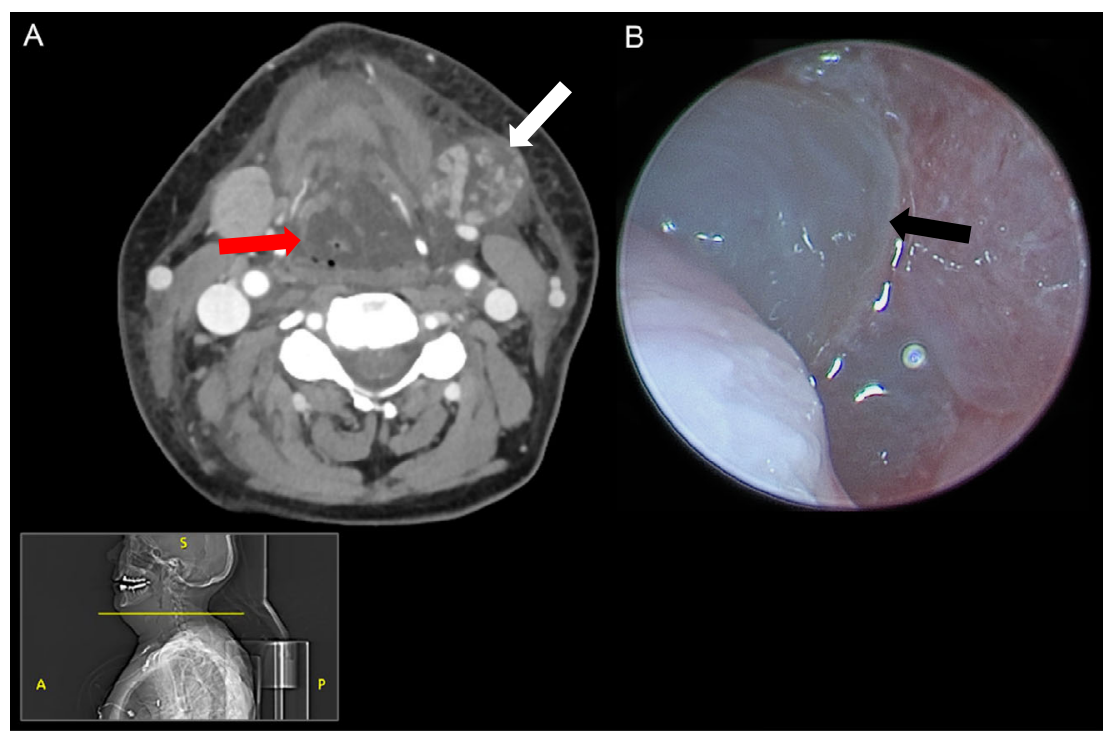

Figure (A) Computed tomography of the neck shows acalculous submandibular sialoadenitis (white arrow) with marked inflammatory changes, edema extending to the epiglottis and aryepiglottic folds (red arrow), and extensive airway narrowing. (B) Flexible nasopharyngoscopy reveals severe billowy edema of the epiglottis (black arrow) with no visualization of the glottic opening

\section{J. J. Van Gompel, MD}

Department of Neurosurgery, Mayo Clinic, Rochester, MN, USA

Department of Anesthesiology \& Perioperative Medicine, Mayo

Clinic, Rochester, MN, USA

e-mail: warner.matthew@mayo.edu

M. L. Carlson, MD

Department of Otorhinolaryngology, Mayo Clinic, Rochester,

MN, USA 
marked inflammatory changes, edema extending to the epiglottis and aryepiglottic folds (red arrow), and extensive airway narrowing.

She developed stridor and respiratory distress, for which intravenous steroids and nebulized racemic epinephrine were administered. Flexible nasopharyngoscopy revealed severe, billowy edema of the epiglottis (black arrow) with no visualization of the glottic opening (Figure, panel B). Emergent surgical tracheostomy was undertaken, additional high-dose intravenous steroids were administered, and she was decannulated on the ninth postoperative day.

Acute submandibular sialadenitis with airway compromise is a rare postoperative complication following retrosigmoid craniotomy. ${ }^{1}$ The presumed mechanism is salivary outflow obstruction in the setting of head rotation and flexion, exacerbated by endotracheal tube compression of sublingual papillae and submandibular ductal outflow. ${ }^{2}$ The swelling often resolves within seven days. Corticosteroids may be used empirically given the high risk of airway compromise. ${ }^{3}$ Consideration should be given to prompt re-intubation in an operating room with the faculty available to perform an emergency tracheostomy if needed. Despite its rarity, anesthesia providers must be aware of this potential complication, advocate for the prevention of extremes of head rotation and flexion, and remain vigilant for postoperative submandibular swelling and airway compromise.

Conflicts of interest None declared.

Editorial responsibility This submission was handled by Dr. Hilary P. Grocott, Editor-in-Chief, Canadian Journal of Anesthesia.

Funding Support was solely from institutional and/or departmental sources.

\section{References}

1. Kim LJ, Klopfenstein JD, FeizErfan I, Zubay GP, Spetzler RF. Postoperative acute sialadenitis after skull base surgery. Skull Base 2008; 18: 129-34.

2. Singha SK, Chatterjee N. Postoperative sialadenitis following retromastoid suboccipital craniectomy for posterior fossa tumor. J Anesth 2009; 23: 591-3.

3. Prabhu K, Ramamani, Nair S, Chacko AG. Acute submandibular sialadenitis as a cause of unilateral neck swelling after posterior fossa surgery in sitting position. Neurol India 2010; 58: 963-4 